\title{
The Role of Loop Height and Design on its Force Characteristics in Alignment of Teeth: A Finite Element Analysis
}

\author{
Atefe Saffar Shahroudi ${ }^{1, *}$ \\ ${ }^{1}$ Department of Orthodontics, Lorestan University of Medical Sciences. Khorramabad, Iran \\ "Corresponding author: Atefe Saffar Shahroudi, Department of Orthodontics, Lorestan University of Medical Sciences. Khorramabad, Iran. Tel: +98-9124070738, E-mail: \\ a-shahroudi@sina.tums.ac.ir
}

Received 2016 January 07; Accepted 2016 January 29.

\begin{abstract}
Objectives: The aim of this study was to assess the effects of different orthodontic vertical loop height and design on its force characteristics at different amount of loop activation by means of finite element method (FEM) analysis.

Materials and Methods: Four 3D FEM models were designed of double vertical open loop (DVOL) and double vertical helical open loop (DVHOL) each of them in two heights of $6 \mathrm{~mm}$ and $7 \mathrm{~mm}$. The loops were modeled in SolidWorks 2006 and then transferred to ANSYS Workbench. The loops were activated in buccolingual direction for 0.1, 0.3, 0.5, 0.7 and $1 \mathrm{~mm}$ simulating an activated multiloop arch wire to align a posterior tooth which is erupted with buccal or lingual inclination. The force delivered at each amount of activation for the four loop designs were measured and compared.

Results: The results of this study showed that the minimum amount of force was delivered by double vertical helical open loop with the height of $7 \mathrm{~mm}$ at the activation of $0.1 \mathrm{~mm}$ which was about 1.06E-01 N. The maximum amount of force was $2.2199 \mathrm{~N}$ which was delivered by double vertical open loop with height of $6 \mathrm{~mm}$ at $1 \mathrm{~mm}$ activation. At each amount of activation the value of exerted force followed this order: DVOL $6 \mathrm{~mm}>$ DVOL $7 \mathrm{~mm}>$ DVHOL $6 \mathrm{~mm}>$ DVHOL $7 \mathrm{~mm}$.

Conclusions: According to this FEM study, considering its limitations, adding a helix in a double vertical open loop as well as increasing the height of loop can reduce the value of delivered force.
\end{abstract}

Keywords: Loop Height, Loop Design, Force, Finite Element Analysis

\section{Background}

Enhancing the quality and quantity of tooth movement is crucial in orthodontics. To move teeth in a controlled fashion and achieve optimum results, various factors should be considered including correct mechanical principles, appropriate interplay between the orthodontic appliance and anatomic structures and the efficacy of tooth movement (1).

An important type of movement in orthodontic treatment is moving a tooth in buccal or lingual direction. If friction free mechanics are applied a double vertical open loop is a choice for this phase. As a general rule, controlled loads are required for controlled tooth movement. Mechanical properties of loops are determined by the balance between forces and moments produced as the loop is activated. This in turn depends on different factors including material properties of the wire alloy, design or shape of the loop and mode of activation $(2,3)$.

The mechanical characteristics of loops depend on not only the moment/force (MF) ratio but also the load/deflection rate. A low load/deflection (LD) rate is desired during tooth movement. However excessive low- ering of maximal elastic load has adverse effects such as permanent loop deformation or breakage during normal oral function $(4,5)$. The addition of helices or changes in the design, shape or size of the loop allows clinicians to more accurately achieve desired moment/force ratio or load/deflection rate for tooth movement. More complex design of springs can reduce load/deflection rate; however, these designs are not widely advocated because of long chair time and inconvenience for the clinician to construct them. One of the most common methods to reduce $L D$ is to increase the height of loop. However, a high loop may irritate oral structures. Accordingly this is prudent to measure the load components produced by different design parameters of loops (6-8).

Finite element analysis (FEA) method is based on the separation of the analysis shape into subdomains through finite elements which is particularly applied when several forces are applied to objects of complex shape. This separation allows a point analysis of the physical behavior of the object under varied loading conditions $(9,10)$. Using FEA, stress and strain response to foreign forces in living structures can be predicted. This method has been successfully applied for biomechanical studies and its efficiency 
has been confirmed (11-14).

The aim of this study was to assess the effects of different loop height as well as adding helixes to a double vertical open loop on the amount of delivered force at different amount of buccolingual activation by means of finite element analysis.

\section{Objectives}

The aim of this study was to assess the effects of different loop height as well as adding helixes to a double vertical open loop on the amount of delivered force at different amount of buccolingual activation by means of finite element analysis.

\section{Materials and Methods}

Four 3D computer models of vertical loops were designed in SolidWorks 2006 (SolidWorks, Concord, Massachusetts, USA). Each contained two loops with $4 \mathrm{~mm}$ distance. The vertical loops were designed to serve as a segment of 0.014 inch multi-loop arch wire designed to align a buccally or lingually displaced premolar tooth. The loop height was $6 \mathrm{~mm}$ and $7 \mathrm{~mm}$. The wire cross section was 0.014 Inch (diameter $=0.35 \mathrm{~mm}$ ) (Figure 1). The 3D models were designed symmetric in form. The models were transferred to the ANSYS Workbench Version 12.1 (Ansys Inc., Southpointe, Canonsburg, PA, USA). Boundary conditions restricted displacements of the nodes at both ends of the loops to prevent rigid body motion. The loops were made of Stainless Steel with Young's modulus of 177000; Poisson's ratio $=0.3$. The models were meshed between 6856 and 11198 nodes and 885 and 1290 elements.

The straight part of the wire between loops was then displaced lingually $0.1,0.3,0.5,0.7$ and $1.0 \mathrm{~mm}$. The force produced in the perpendicular direction to the loop plane was then evaluated (Figure 2).

\section{Results}

Two designs of double open vertical loop with and without helix was modeled in this study each of them in two lengths of $6 \mathrm{~mm}$ and $7 \mathrm{~mm}$. The measurements in different amount of activation showed that the minimum amount of force was delivered by double vertical helical open loop with the height of $7 \mathrm{~mm}$ at the activation of 0.1 $\mathrm{mm}$ which was about 1.06E-01 N. The force was increased to $1.0633 \mathrm{~N}$ in $1 \mathrm{~mm}$ of activation. These findings were between $0.1409 \mathrm{~N}$ and $1.4096 \mathrm{~N}$ for DVHOL [6 mm].In DVOL [6 mm], the findings were higher and started from $0.221 \mathrm{~N}$ and increased to $2.2199 \mathrm{~N}$ in $1 \mathrm{~mm}$ of activation. In DVHOL
[7 mm], force finding were between $0.163 \mathrm{~N}$ and $1.6358 \mathrm{~N}$. (Figure 3).

The maximum amount of force was $2.2199 \mathrm{~N}$ which was generated by DVOL [6 $\mathrm{mm}$ ] at $1 \mathrm{~mm}$ activation. The force values by four types of loops at five different amount of activation are shown in Table 1.

As it is illustrated in Figure 4, the amount of force increased as the amount of activation raised. At each amount of activation the value of exerted force was the highest for DVOL with $6 \mathrm{~mm}$ height followed by $7 \mathrm{~mm}$ DVOL, $6 \mathrm{~mm}$ DVHOL and $7 \mathrm{~mm}$ DVHOL respectively.

\section{Discussion}

When a loop, spring or power chain is applied to exert orthodontic tooth movement, the ability of the appliance to produce a particular type of movement depends on the moment/force ratio or on the load/deflection rate that it can deliver. For an orthodontic loop, the load/deflection rate, also known as the force/deflection rate, defines force per unit of activation. A low load-deflection rate and a high moment/force ratio has been always mentioned as favorable criteria for an orthodontic loop (15-17).

To compare the LD rate of two loops one can measure the force generated by them at the same amount of deflection. The results of this study demonstrated that at a specific amount of buccolingual activation, the maximum amount of force was delivered by double vertical open loop without helix with the height of $6 \mathrm{~mm}$ and the minimum force was generated by $7 \mathrm{~mm}$-high double vertical open loop with a helix. In other words, the former loop had the highest LD rate and the latter had the least. Actually in this FEM study the effect of three different parameters was evaluated on the force generated by a double vertical open loop: The height of the loop, the effect of adding helix and the amount of activation or buccolingual deflection. According to the results of this study the higher the loop the lesser the amount of force it deliver. This means that at similar circumstances, higher loops had lower LD rate. Faulkner et al. (1989) reported the same findings when studied the effect of parameters on the force/moment systems produced by T-loop retraction springs by using the finite element method. They reported larger moment to force ratios as the height of loops increased (18). Similarly Chen et al. (2000) stated that increasing the vertical or horizontal dimension of a T-loop reduced the spring's $L D$ rate (19).

Comparing double vertical open loops with and without helix in this study demonstrated that adding a helix would result in lower force generated by the loops at similar amount of deflection. This reduction of LD rate is due to incorporating larger amount of wire in the loop with a 
A

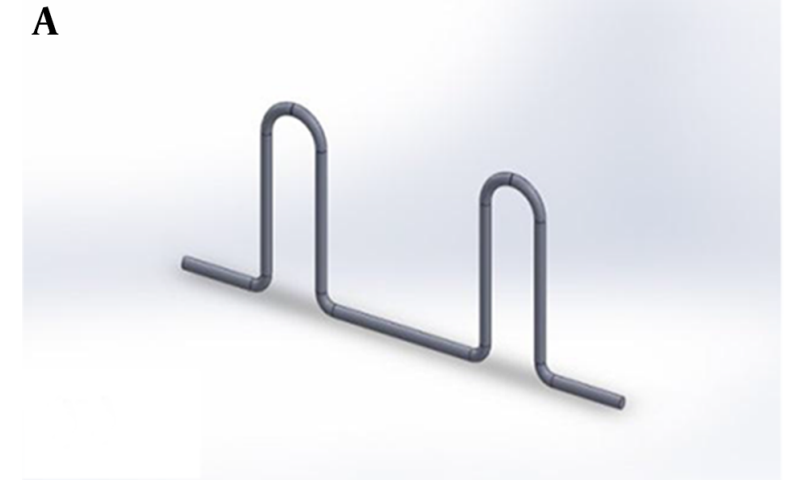

B

A, Simple double vertical open loop; B, double vertical open loop with helix.

Table 1. Force exerted by Different Types of Loop at Different Amount of Buccolingual Activation $(\mathrm{N})^{\mathrm{z}}$

\begin{tabular}{|c|c|c|c|c|}
\hline Activation & $\operatorname{DVOL}(7 \mathrm{~mm})^{\mathbf{a}}$ & $\operatorname{DVOL}(6 \mathrm{~mm})^{\mathrm{a}}$ & $\operatorname{DVHOL}(7 \mathrm{~mm})^{\mathrm{a}}$ & $\operatorname{DVHOL}(6 \mathrm{~mm})^{\mathrm{a}}$ \\
\hline 0.1 mm & 0.16385 & 0.22199 & $1.06 \mathrm{E}-01$ & 0.14096 \\
\hline $0.3 \mathrm{~mm}$ & 0.49154 & 0.66596 & 0.31899 & 0.42289 \\
\hline $0.5 \mathrm{~mm}$ & 0.81923 & 1.1099 & 0.53165 & 0.70481 \\
\hline $0.7 \mathrm{~mm}$ & 1.1469 & 1.5539 & 0.74431 & 0.98674 \\
\hline
\end{tabular}

${ }^{2}$ Abbreviations: DVOL double vertical open loop; DVHOL, double vertical helical open loop.

${ }^{\mathrm{a}}$ The number in parenthesis refers to the height of loop in millimeter

relative constant size. Thus, in addition to increasing the height of a vertical loop, the MF ratios can be increased by changing the loop design. Although Faulkner et al. (1989) reported the addition of helices at the bends did little to alter the springs' mechanical characteristics (18). Many other authors believed that optimizing the loop design can provide a constant MF ratio, a light and constant force throughout the entire activation range of a closing loop, and a constant low LD rate $(5,17,20)$.

In comparison of the effect of increasing loop height and the effect of placement of helix in the loop in this study, it was shown that at $1 \mathrm{~mm}$ deflection, the difference between the force of $6 \mathrm{~mm}$-high DVOL and $7 \mathrm{~mm}$-high DVOL was very slightly greater than the difference between the force of $7 \mathrm{~mm}$-high DVOL and $7 \mathrm{~mm}$-high DVHOL (0.5814 N and $0.5752 \mathrm{~N}$ respectively) (Table 1, Figure 4). In this issue, Blaya et al. (2009) compared the mechanical behavior of different orthodontic retraction loops and concluded that the alloy of the wire and the height of the loop would be more important than the loop design (21). In addition to loop height and designs several factors have been shown to affect the force exerted by a loop spring including the alloy of the wire, the cross-section of a wire, the mode of loop preactivation and the temperature $(19,22,23)$. Not to be lost in this discussion, it is worth mentioning that most of the studies on biomechanics of orthodontic loops, addressed closing loops which were activated in mesiodistal direction and the double vertical loop which is activated in buccolingual direction and was applied in this study has not receive much attention in the literature. Menghi et al. (1999) analyzed the force systems developed three designs of loops acting for first order irregularities and buccolingual movement and concluded that rectangular loop was preferred to L-loop and T-loop for making first order corrections (24).

This study was an FEM analysis and it is suggested to conduct some studies to evaluate this subject in clinical condition.

\subsection{Conclusions:}

According to this FEM study, adding a helix in a double vertical open loop as well as increasing the height of loop can reduce the value of generated force at similar amount 

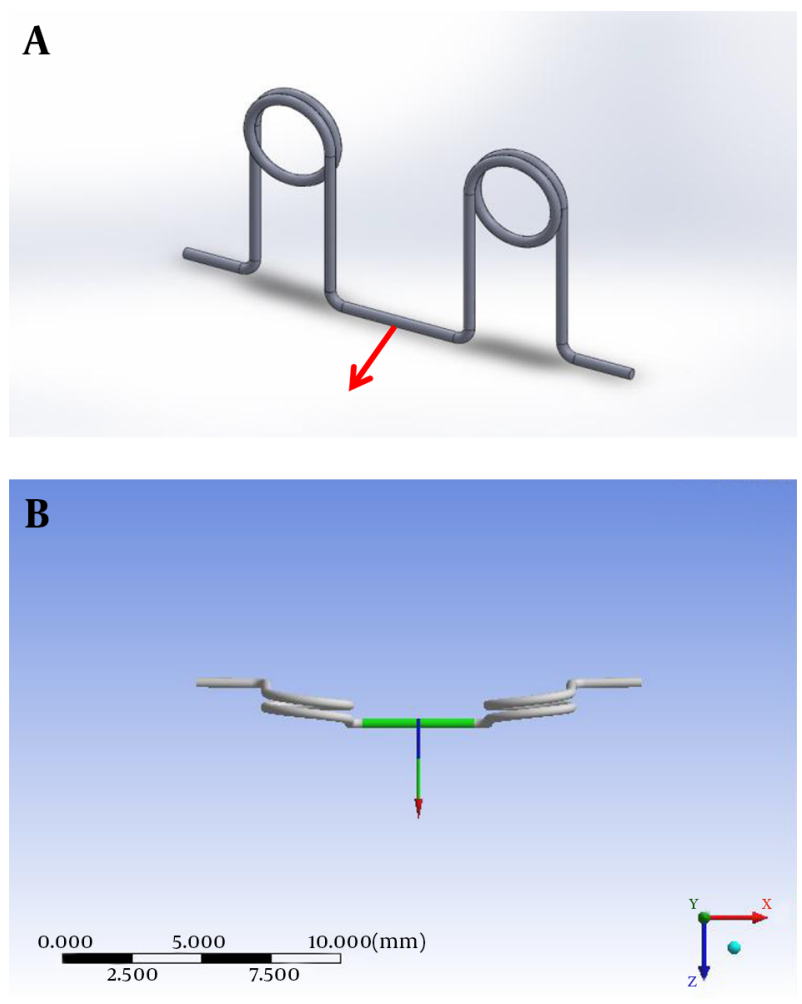

Figure 2. Activation of the Loop

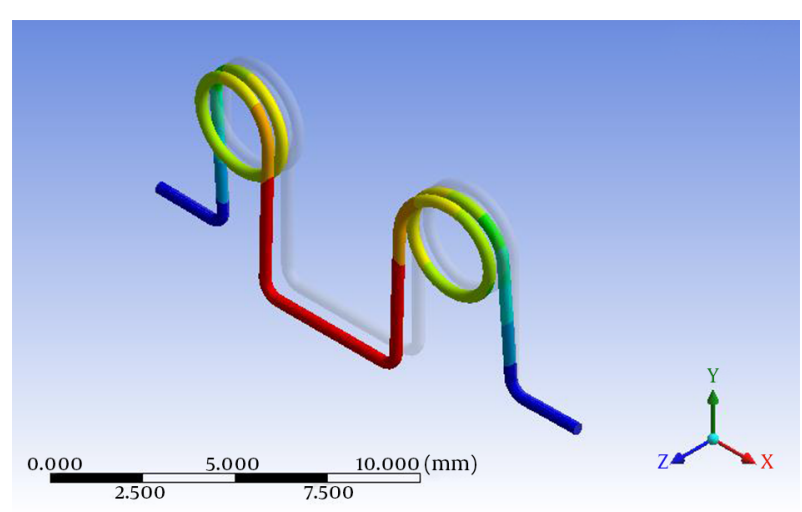

Figure 3. The Deformation of the Double Vertical Helical Open Loop in Activation

of buccolingual deflection thus drops the load deflection rate of the loop spring.

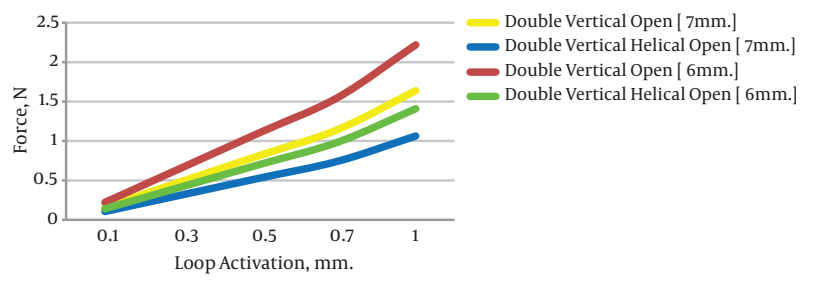

Figure 4. Force Modification With Loop Height and Presence or Absence of a Helix

\section{References}

1. Gjessing P. Controlled retraction of maxillary incisors. Am J Orthod Dentofacial Orthop. 1992;101(2):120-31. doi: 10.1016/08895406(92)70003-S. [PubMed: 1739066].

2. Martins RP, Buschang PH, Gandini LJ. Group A T-loop for differential moment mechanics: an implant study. Am J Orthod Dentofacial Orthop. 2009;135(2):182-9. doi: 10.1016/j.ajodo.2007.02.055. [PubMed: 19201324].

3. Staggers JA, Germane N. Clinical considerations in the use of retraction mechanics. J Clin Orthod. 1991;25(6):364-9. [PubMed: 1939634].

4. Hayashi K, Araki Y, Mizoguchi I. Nonlinear large-deflection analysis of orthodontic wires. Angle Orthod. 2004;74(1):112-7. doi: 10.1043/00033219(2004)074<0112:NLAOOW>2.0.CO;2. [PubMed: 15038499].

5. Burstone CJ, Koenig HA. Optimizing anterior and canine retraction. Am J Orthod. 1976;70(1):1-19. [PubMed: 1066042].

6. Rose D, Quick A, Swain M, Herbison P. Moment-to-force characteristics of preactivated nickel-titanium and titanium-molybdenum alloy symmetrical T-loops. Am J Orthod Dentofacial Orthop. 2009;135(6):75763. doi: 10.1016/j.ajodo.2007.06.015. [PubMed: 19524835].

7. Kum M, Quick A, Hood JA, Herbison P. Moment to force ratio characteristics of three Japanese NiTi and TMA dosing loops. Aust Orthod J. 2004;20(2):107-14. [PubMed: 16429881]

8. Keng FY, Quick AN, Swain MV, Herbison P. A comparison of space closure rates between preactivated nickel-titanium and titaniummolybdenum alloy T-loops: a randomized controlled clinical trial Eur J Orthod. 2012;34(1):33-8. doi: 10.1093/ejo/cjq156. [PubMed: 21415288].

9. Huiskes R, Chao EY. A survey of finite element analysis in orthopedic biomechanics: the first decade. J Biomech. 1983;16(6):385-409. [PubMed: 6352706].

10. Jayasudha K, Hemanth M, Baswa R, Raghuveer HP, Vedavathi B, Hegde C. Traumatic impact loading on human maxillary incisor: A Dynamic finite element analysis. J Indian Soc Pedod Prev Dent. 2015;33(4):302-6. doi: 10.4103/0970-4388.165680. [PubMed: 26381632].

11. Geramy A. Apical third morphology and Intrusion force application 3D finite element analysis. J Dent Tehran Uni Med Sci. 2007;4(3):130-4.

12. Geramy A, Ommati-Shabestary GH, Eghlima L. Influence of the angle of cervical convergence on stresses to the PDL of abutments:A 3D analysis using finite element method. J Dent Tehran Uni Med Sci. 2007;4(1):15-20.

13. Geramy A, Ghadirian H. Comparison of methods used to correct a lingually tilted mandibular molar: 3-D analysis using the finite element method (FEM). Aust Orthod J. 2008;24(2):96-101. [PubMed:19113073].

14. Geramy A. Alveolar bone resorption and the center of resistance modification (3-D analysis by means of the finite element method). Am J Orthod Dentofacial Orthop. 2000;117(4):399-405. [PubMed: 10756265].

15. Burstone CJ, Baldwin JJ, Lawless DT. The application of continuous forces to orthodontics. Angle Orthod. 1961;31:1-14.

16. Yang TY, Baldwin JJ. Analysis of space closing springs in orthodontics. JBiomech. 1974;7(1):21-8. [PubMed: 4820648]. 
17. Vanderby RJ, Burstone CJ, Solonche DJ, Ratches JA. Experimentally determined force systems from vertically activated orthodontic loops. Angle Orthod. 1977;47(4):272-9. doi: 10.1043/00033219(1977)047<0272:EDFSFV>2.0.CO;2. [PubMed: 270295].

18. Faulkner MG, Fuchshuber P, Haberstock D, Mioduchowski A. A parametric study of the force/moment systems produced by T-loop retraction springs.J Biomech. 1989;22(6-7):637-47. [PubMed: 2808446].

19. Chen J, Markham DL, Katona TR. Effects of T-loop geometry on its forces and moments. Angle Orthod. 2000;70(1):48-51. doi 10.1043/0003-3219(2000)070<0048:EOTLGO>2.0.CO;2. [PubMed: 10730675].

20. Braun S, Marcotte MR. Rationale of the segmented approach to orthodontic treatment. Am J Orthod Dentofacial Orthop. 1995;108(1):1-8 [PubMed: 7598097].

21. Blaya MB, Westphalen GH, Guimaraes MB, Hirakata LM. Evaluation of tensile strength of different configurations of orthodontic retraction loops for obtaining optimized forces. Stomatologija. 2009;11(2):66-9. [PubMed: 19773631]

22. Caldas SG, Martins RP, Galvao MR, Vieira CI, Martins LP. Force system evaluation of symmetrical beta-titanium T-loop springs preactivated by curvature and concentrated bends. Am J Orthod Dentofacial Orthop. 2011;140(2):e53-8. doi: 10.1016/j.ajodo.2010.11.022. [PubMed: 21803234].

23. Martins RP, Buschang PH, Viecilli R, dos Santos-Pinto A. Curvature versus v-bends in a group B titanium T-loop spring. Angle Orthod. 2008;78(3):517-23. doi: 10.2319/030207-109.1. [PubMed: 18416618].

24. Menghi C, Planert J, Melsen B. 3-D experimental identification of force systems from orthodontic loops activated for first order corrections. Angle Orthod. 1999;69(1):49-57. doi: 10.1043/00033219(1999)069<0049:DEIOFS>2.3.CO;2. [PubMed: 10022185]. 